\title{
The Socio-cultural, Financial and Education Problems of International Postgraduate Students in Turkey*
}

\author{
Osman Titrek*, Ali Erkiliç, Emrah Süre, Mehmet Güvenç, Nurcan Temür Pek
}

Faculty of Education, Sakarya University, Turkey

Copyright $\bigcirc 2016$ by authors, all rights reserved. Authors agree that this article remains permanently open access under the terms of the Creative Commons Attribution License 4.0 International License

\begin{abstract}
The aim of this study is to analyze and investigate the predicaments that are categorized by the investigators according to education and life conditions of postgraduate international students in Sakarya University. Qualitative research method has conducted in this research and standardized and tightly structured interview form was used to address questions as a data collection tool in the study. During the interview, objectively investigators helped the participants because they were not good at speaking Turkish. The study sample included 20 postgraduate international students from several departments at the institutes of natural and applied sciences and social sciences of Sakarya University, 2015 - 2016 academic year as voluntarily. Maximum range sample technique was used in the identifying of the study group. In the analytical part of the study descriptive analysis technique that is one of the qualitative research techniques was used to facilitate the thematic classification of data's and get a detailed description of condition. The result of the study determined that international students were not living desired level economically and homesickness also other serious problem at the beginning of the process. Participants did not have many difficulties about harboring. In the title of human relations international students stated that Turkish people and Turkey close themselves; also they did not have problems about it generally about racism. They could not communicate face to face often. Instead they used telephones, internet etc. devices to communication. Participants expressed that they did not have problems about the Turkish food generally, moreover they found close to Turkish foods. While clothing case it was determined that there was no problem about clothing, everyone could wear traditional clothes what they wanted easily, also they did not suffer from their clothing style. About the traditions statement, their closeness of Turkish culture came into prominence. It was identified that participants could easily perform situations that include their traditions. It was not confirmed that they got into trouble about their religious belief. Under the education topic difficulty of learning language was
\end{abstract}

emphasized, so they expressed even if just a smidgen their challenges about both lectures and daily life. They said that they took support from their faculty members and classmates to overcome this hardship.

Keywords Foreign Students, Economical Situation, Socio-cultural Adaptation, Educational Problems

\section{Introduction}

Nowadays globalization shows its effects in all spheres swiftly. Information got from wherever in the world can spread to societies expeditiously or people can gain own experiences by getting at the source of information personally. This swift conversion effects are felt in the education field and countries wants to have a voice by playing a part at this market. In fact Turkey is not be unconcerned the issue and the first international students were permitted with "The Exam of Foreign Student" in 1981. International students present countless significant opportunities to countries. Expenditures are made during their period of study, rise of intercultural dialogue and tolerance thanks to their variation, and after the graduation their sympathy and emotional bond to countries make them volunteer ambassadors. These are several opportunities of international students [7]. Beside all these opportunities international students have a certain number of problems. The orientation of new environment, communication difficulties, disagreements about social and ethical values, relating social and vocational, feeling out of place, adjustment of new education system are some of the problems of international students come face to face. [5].

When we look at the literature, Talebloo [15] researched international students in Malaysia, Lewis et al. [9] surveyed international students in Taiwan and the last study organized by Titrek et al. [16] for determining challenges in Turkey and all of them concluded that international students are faced 
with four common categories of problem, which are facilities (accommodation, transportation, food, and libraries), the social environment (culture, communication, and English difficulties, homesickness, loss of social support and feelings of social exclusion), academic difficulties (the academic system, lectures and methodology, faculty supervisors), and financial issues. It is seen that international students' issues do not have educational background in Turkey, therefore there is a lack of literature research about the international students. The study of Policy, Economy, Society Survey Foundation[13] mentions about the countries which follow the policies and tendency of world about the international students. It brings forward proposals about the problems and experiences of students after interviews with the related institution representatives and students. In the study of Kiroğlu and friends [8] socio -cultural and economic problems of international students were analyzed in Turkey. They confirm the financial in capabilities and homesickness with the research including 15 students. Annaberdiyev [1] investigates psychological attitude for help-seeking, basic psychological needs and psychological adaptations of students from Turkish Republics and Turkish university students. Otrar et al. [10] examine relationship between the sources of stress, coping skills with the mental health by studying on Turkish and relative societies. Göçer and Moğul [6] refer to studies about teaching Turkish to international students with a general point of view and indicate problems and solution offers by taking into consideration the studies of this field. Paksoy et al. [11] make a survey one to one with the international students. It has been searched whether learning Turkish in Turkey or their own country and having friends from own country in Turkey can affect the success of international students or not. According to research results having friends from their own countries affects the success of international students. This study seeks answers the following problems and sub problems by taking into consideration researches.

It is clear that foreign student numbers have been increasing in Turkey and more researches are necessary to solve their problems. That's why the main problem of this research is what the socio-cultural, economic and educational problems of postgraduate international students are in Turkey. In this context, the following sub problems will be searched:

Sub problem 1: What are the socio-cultural problems of postgraduate international students in Turkey?

Sub problem 2: What are the economic problems of postgraduate international students in Turkey?

Sub problem 3: What are the educational problems of postgraduate international students in Turkey?

\section{Methodology}

The study was conducted qualitative research method and on the data collection stage interview technique was used.
Because participants cannot speak Turkish fluently, research data was collected through the structured interview form which is one of the qualitative data analysis techniques. During the application of forms one of the researchers accompanied the participants for making questions more understandable. Although the population of the study consisted of all postgraduate students of Science and Social Sciences Faculties at Sakarya University, 20 students was chosen for the represent the maximum various sample when we considered the time and cost. Authority opinions were asked for the rise the validation of this study. Questions in the form were evaluated and improved with the authority before the application. Moreover, mentioned literature researches were examined to rise the validation of study and in this direction questions were prepared. In terms of the study confidence, observation forms were designed according to categories, socio-cultural, economic and educational problems. In this way possible decoding errors and misunderstandings were tried to prevent. In the study, answers of participants were quoted for provide the internal confidence of research. Descriptive analysis technique was used in the analysis section. Because descriptive analysis is a kind of qualitative analysis provide simple summaries and comments about the data is obtained by the various data collection techniques. In this research model researcher can give place to quotes directly on the purpose of image the opinions of the participants in a dramatic way. The basic aim of this kind of analysis presents the evidences to reader in an interpreted and outlined way. [17].

\section{Results}

We explained the results based on the problem fields mentioned below.

\subsection{Economic Results}

International students express having financial problems generally. Large majority of student's state that they get a fellowship from The Department Turks Abroad and Related Communities but it is not sufficient for them. Students who do not financial problems express that they work extra jobs or organize their life according to their incomes. Food is given at university, student discounts on bus and other special discounts for students help making life easier for them.

Fellowship is not sufficient; It hardly covers my food and transportation expenses. (S2)

No. It is not sufficient, It is not enough to cover my needs easily.(S5)

It is not sufficient .It can not afford my social activities.(S14)

My family remits me money even if just a smidgen. I have a part time job here. (S17)

International students state that their families are second 
financial source when fellowship is insufficient. They want some extra money from their families. However, it cannot afford for their expenses because of differences between the value of their money and Turkish Lira.

I get help from my family when I have extra expenses like going and coming my country or buy some books.(S1)

Yes, I do. But I have difficulties because the value of our money is low here. (S5)

Generally not. But I get support from my family when I need more.(S6)

Yes, I get support from my family.(S8)

Yes. My family can cover all my expenses in Turkey.(S16)

I get some financial support from my family.(S18)

Unfortunately, my family has financial problems, so I couldn't get help.(S19)

When fellowship is not sufficient, I get some help my family (S20)

International students express that even the fellowship is not sufficient; they keep living only this money. Because of their families bad financial situations they do not want their support, they maintain their lives by retrenching other expenses.

It is sufficient. It can afford my expenses here. I do not get help from my family because their financial situation is worse than me.(S3)

Even It is not completely sufficient, I try because I do not have other incomes.(Ö4)

I do not get financial support from my family.(S7)

Fellowship is sufficient for my needs.(S20)

International students signify that they are pleased to opportunities in Turkey generally. In fact, they do not have same opportunities even their own countries.

I am pleased to opportunities here exceedingly.(S1)

I am happy with the conditions here, I did not have this kind of possibilities even in my own country.(S2)

I am so pleased to conditions, everything is considered for us.(S3)

I am pleased with opportunities. I can afford my needs even it is not adequate.(S4)

I am pleased with conditions. In fact it is better than my country.(S16)

I consider that conditions are so good but I can not benefit too much because of my financial problems. (S17)

I think that the conditions are more useful than my country(S19)

International students state that conditions are not great, the better opportunities must be provide. Moreover, they express that facilities are normal, it is necessary to improved facilities.

In my opinion opportunities are mid range.(S9)

Opportunities are good but they should be better.(S10)

Everything happens slowly here.(S11)

It could be greater. (S14)

\subsection{Harboring}

International students figure that they do not have harboring problems. Most of the students stay in dormitory. Other students are not live in dormitory that they stay in guesthouses and houses. They do not have problems of finding places; they get support about harboring from their friends living here.

I am staying in the dormitory.(S1)

I am staying in a special dormitory in Hendek .(S17)

I stay in dormitory.(S5)

I did not have problem. I had a friend here he helped me.(S3)

I stay a house near the school.(S16)

I did not have problem. There were people introduce there.

I visited and decided to stay there.(S17)

I didn't. Because I came here with my friend who came to here previously.(S7)

I stay at a furnished house. I joined my friends later.(S19)

International students express that they have problems about harbouring and finding location of dormitory. In fact, very few students state that people do not want to rent their houses to students.

No, I did not have problem. Transportation of dormitory was easy.(S5)

Yes. people I asked the location of dormitory also did not know the location of it.(S1)

Yes I had difficulty about finding dormitory because of communication problems.(S2)

I had problems. I did not know the location and I could not find dormitory. (S15)

We had troubles to find place. Some people did not want to rent houses to students.(S20)

\subsection{Human Relations}

International students relations were examined with two sub titles including exclusion and friend relationship

Exclusion: International students express that they are not exposed to exclusion generally, people behave well, and they think that people take care of them.

I did not have exclusion. I have lovely friendship here.(S1)

No. I did not. Turkish people are fine.(S2)

No. I did not. They behave me as a Turkish citizen.(S3)

No, I did not have problems like that.(S9)

No, I did not come across exclusion.(S10)

No, I am Muslim so I do not have exclusion.(S11)

I did not. Turkish people are helpful.(S13)

I do not have enough time to spend people but I do not have exclusion.(S17)

Turkish people show sincerity to us. We have good relationships.(S19)

An international student says he has not been behaved directly racist manner but he feels exclusion with the eyes and attitudes.

I do not have exclusion by students and teachers at school but glances of people discomfort me (S4) 
Friendship: Most of the international students clarify that firstly they choose their friends among their own citizens, secondly they choose their friends among other international students, and thirdly they choose Turkish friends. They state that they get on well with their own citizens and other international students because they have common feelings, thoughts and troubles.

Primarily I prefer my friends among own citizens because I communicate with them easily.(S1)

I mostly prefer own citizens but I have many Turkish friends (S3)

I prefer African friends (S13)

I spend most of my time with my friends.(S14)

Primarily I prefer African friends. It is easy to speak and get on well with them.(S17)

International students express that they make friends from different countries; it does not matter to create friendship.

It does not matter. I have friends from both my country and Turkey.(S2)

Country is not important for me.(S9)

They are from both my own country and Turkey.(S11)

I have friends all countries. I do not presences. Turkish friend would be good to learn Turkish.(S18)

I do not prefer specific country to determine my friends. I am on good terms with all .(S20)

\subsection{Homesickness}

Almost all of the International students indicate that they feel homesick. They emphasize that the most desirable point about the homesickness is their families. It shows that they miss their friends and hometown. A few students mentioned that in the beginning they desired mostly but in the process of time they get used to their friends in Turkey and do not feel homesick as in the beginning. Students utter their opinions about homesick like these:

I miss my family and brothers. We get in touch by the internet.(S17)

No, I don't feel so because of the place I live here.(S19)

I think everyone feels homesick when they move away from their home.(S20)

I miss everyone and everything but unfortunately I could not go very often.(S5)

Yes, I feel homesick a lot in the beginning, but now it is not as much as before.(S9)

I desire both my family and my friends.(S13)

\subsection{Food}

However international students' opinions show distinctness about the food culture in Turkey, most of the students report that they get used to Turkish food culture and they have no trouble about it. The following statements are views of international students:

Yes, I got used. When I ate first I could not appeal to the taste buds. Later they become my irreplaceable foods.(S2)

I do not have trouble with the foods. They are
delicious.(S13)

Yes, I get used foods.(S10)

There are restaurants near my staying I usually eat there.(S16)

I do not have problems much. I fulfill my needs in dormitory or outdoor.(S17)

Some of the participants state that they become accustomed to Turkish foods and they do not have difficulties eating and having foods. On the other hand there are participants do not used to Turkish foods. Students' views are as below:

I have difficulty in eating Turkish foods. I hunger my traditional foods.(S7)

I could not find foods belonging to my own country here (S2)

We could not cook what we want in dormitory, also in summers there isn't any food service in the dormitory.(S14)

\subsection{Clothing}

While some of the participants express that they do not have troubles about clothing in Turkey, almost half of the participants have difficulty in clothing. Opinions of international students who grateful to clothing issue are as below:

No, I do not have any problem about it.(S19)

I do not have difficulty in finding clothes but sometimes I cannot afford to buy clothes.(S20)

No. I do not. Because we wear same clothes in our country, too. (S1)

No. I do not. I can find everything what I want here.(S2)

No, I usually satisfy my clothing needs.(S10)

International students' reasons of having trouble about clothing that they could not find their traditional clothes here. Their views about this issue are as below:

I get into trouble finding traditional clothes.(S5)

I could not find as my own clothes here.(S11)

Our clothes are different, so we cannot find same clothes here.(S15)

It is said that most of the international students do not get into trouble about their traditional clothes and their dressing style. Their views about this issue are as below:

I wear large t-shirts and jeans. It is hip hop style. There is no problem about it.(S16)

I am not faced clothing problem when I wear my traditional clothes. Sometimes I only realize their stares.(S17)

We have rather good reactions.(S19)

I did not wear our traditional clothes. I don't think it would be a problem, even if I wear traditional clothes.(S1)

\subsection{Traditions}

It is stated that most of the international students keep traditions alive in Turkey and they do not have serious adaptation problems between their own traditions and Turkish traditions. Furthermore, a few students who have 
problems about this issue express that in daily life some behaviors have different meanings in their traditions. Participant's views about this issue are as below:

Here, I have friends from my country. When we come together with my friends not others, we implement our traditions. (S16)

I do not have problem about it. People are more helpful and understandable here. They always help about everything. (S17)

No, I do not have problem. Turkish people have great traditions like kissing hands of elders.(S4)

I do not have problem. Because the religion of us is the same with Turkish people, most of the traditions resemble each other.(S5)

Yes I have troubles because of my different religion.(S7)

Almost all the international students say that they do not have problems about their religious life in Turkey. The followings are their views about this issue:

I do not have any problem about it. Turkish people and other international students appreciate this issue.(S8)

I don't have problem because I am a Muslim (S1)

Yes I had some problems. I could not make celebrations because it is not official here.(S4)

No I did not. I pray easily here.(S6)

\subsection{Education}

International students problems collected under educational title are examined into 3 (three) category: Turkish Education, Lectures, Teachers.

Turkish education: International students indicate that Turkish education is inadequate to daily speaking and understanding, understanding the lessons and academic studies. It is predicated that they want to learn Turkish in extended period of time and free of charge at universities. (S3)

It is not sufficient. I could not learn Turkish completely.

No, It is not adequate. I can speak with my friends but it is hard to understand lessons.(S2)

It is not sufficient for the level of a university, I am unsuccessful to academic education.(S4)

It is not sufficient for university education (S8)

It will be useful to get more Turkish education for the lessons.(S13)

No, It is not. Every time grammar is wanted but I am not good at.(S15)

International students indicate that Turkish education is adequate to daily communication, understanding the lessons and academic studies.

I think, Turkish education is sufficient to satisfying my needs.(S1)

It is sufficient, I can understand my friends and teachers easily.(S5)

Yes, It is sufficient enough to communicate.(S6)

In my opinion, teaching of Turkish is normally.(S10)

The more I practice Turkish, the more I enhance my Turkish. Sometimes I can find it difficult but the education was useful for me.(S16)

I think Turkish education is good. I need speaking practice.(S18)

Lectures: It is stated that most of the students have difficulty in learning verbal lessons and academic Turkish. Also the most difficult course subjects international students do not understand are Turkish grammar and Ataturk's principles and reforms.

Grammar lesson is hard. I am bad at learning passive voice and causative form.(S1)

History and Grammar lessons are challenging.(S2)

I got some troubles in lessons because of my inadequate Turkish speaking.(S3)

I get in trouble when I read Academic papers. I was really bad at verbal lessons.(S4)

Yes. Turkish Literature is very difficult.(S6)

I could not understand complicated topics.(S12)

Yes It is difficult to understand but my friends help me. I have to study more.(S16)

Sometimes I get in trouble because my Turkish is not well, I could not understand meanings of some words.(S20)

Teachers: It is clear that international students do not have any communication problems with their teachers. Teachers help students by speaking English when the subjects are unexplained.

Yes, they can communicate us with other foreign languages. They know English and Arabic.(S2)

Yes. They explain meanings of the words in English to make clear the subject.(S4)

I can speak different languages with my teachers.(S5)

I do not have communication problems with my teachers sometimes they teach subjects in English, too.(S6)

They can speak English and some of them help us.(S15)

My English level is advanced so sometimes I explain myself in English. When some of teachers speak English, It will be useful. (S19)

It is expressed that some of the international students get troubles about communication with teachers. Teachers do not have advanced English skills so it will be problem communicate each other.

Although I can speak some teachers, sometimes I cannot communicate others because they know only Turkish.(S1)

You cannot communicate with teachers because they do not want to speak foreign language (S3)

Yes, In the beginnings I have some troubles.(S7)

\section{Results, Agreement, Advices}

This paper examined the problems of international students who are doing their post-graduate studies at Sakarya University in Turkey. It is known that problems, if not eradicated or decreased, can affect the learning processes of foreign students more. This can lead to failure, frustration, and some of them even decided to return home([15],16]). Other recent study by Buliæ [2] also indicated that some international students in Turkey are facing difficulties, which 
sometimes results in their leaving everything and going back home. From the findings, this study shows that these challenges are still occurring and that long and short-term strategies should be applied to overcome these challenges. These challenges teach students new perspectives and also develop their lifelong learning skills in recent years, universities and possibilities of universities create a new global financial area to countries [4]. When we observed this study results, we are seeing similar findings with other studies we mentioned above. Based on this research results, economic activities see the international students as normally a member of this system. However Turkey is a new in this segment it wants to be efficient. In the research it is clear that international students have financial problems about transportation, harboring and food etc. Despite fellowship and support students programs in our country, the needs of the students could not be satisfied easily. Harboring and food is containing the large proportion of students' expenses can be minimized by the government funds and dormitory services. In those conditions students can benefit from the possibilities of education comfortably in Turkey by the reduction of costs.

There are so many student clubs in the structure of universities. These clubs both offer to build and improve good relationships with people to international students and a facility to contribute social wealth for our country. It is quite important to obtain our country's repetition and honor with the favorable attitudes and behaviors of international students after they return their own countries. International students' communication problem with their families is another main problem that is established in the study. To reach their goals motivation is the essential phenomenon for the international students. It is unquestionable fact that students who have homesickness long period of time suffer from being well motivated. This poor situation will disappear with the small regulation that at least the cost of transportation is supported financially by associations, endowments and universities.

International student's problems about harboring are identified in the study of Çağlar[3]. In this study same indications are found. The issues of harboring and food can be a serious problem even a student in our country, it also constitute a big problem international students. Reduced price can be applied for the international students who benefit from credit and dormitories institution for foods. Moreover local authorities' should provide necessary opportunities for the international students. This situation should be understood as a natural right for the international student because they create both social and financial mobility. The most determinant factor about exclusion and prejudice of international student is the social and geographic distances ([12]; [14]). Most of the researches show that international students do not have difficulty in keeping their traditions alive and religions in Turkey. Hospitality of our country's people holds on with tolerance and empathetically ways since early dates. Different traditions and beliefs are not a problem on the contrary they are both color and wealth and people behave international students warm and sincerely. Thus, exhibition of positive attitudes show this situation clearly. It would be more meaningful to give them support about introducing their own civilization and culture.

Most of the participants of this study find adequate to learning a foreign language. The problems of adaptation and communication become apparent due to difficulties of learning a foreign subject even the training is adequate for the international students. Within this context to learn foreign language the practice of Turkish can be actualize by creating speaking groups through students clubs, courses and various activities. Students who verbalize themselves in Turkish can easily compromise with their teachers and friends by the way communicate. Favorable of this situation return back as a motivation for the international students. It is doubles that students who focused the education would be successful. So our country become center of attraction, Turkey will expand its part at the education market of international students. Based on the findings and discussions, it can be concluded that there are some challenges experienced by international students while pursuing their education at Sakarya University in Turkey. Among the main problems are related economic issues, harboring, language and homesickness, but they claim that they have not got socio cultural problems. They used to socio-cultural issues, customs, meals and they have good Turkish friends. Turkish friends are helpful and there is no racism towards them in Turkey.

\section{Note}

*The abstract of this paper was presented at 2nd International Conference on Lifelong Learning and Leadership for All (ICLEL-16), in Liepaja on July, 21-23, 2016.

\section{REFERENCES}

[1] Annaberdiyev, D. (2006). The Investigation about Psychological attitude for help-seeking, basic psychological needs and psychological adaptations of students from Turkish Republics and Turkish Universities Unpublished postgraduate thesis, Ege University, Faculty of Education, İzmir.

[2] Buliæ NR 2015. International students in Turkey: Main problems related to poor academic performance. Journal of Psychology and Clinical Psychiatry, 2(5): 1-2.

[3] Çağlar, A. (1999). The problems of students from Turkish republics and relative communities in Turkey. TODAİE The Journal of Public Administration, 32 (4), 133-169.

[4] De Wit, H. (2002). Internationalization of higher education in the United States of America and Europe: A historical, comparative and conceptual analysis. Westport, CT: Greenwood. 
[5] Gibson, J. T. et al. (1991). Youth and culture: A seventeen nation study of perceived problems and coping strategies, International Journal For The Advancement of Counselling, 14(3), 203-216.

[6] Göçer, A. \& Moğul, S. (2011). International Periodical For The Languages, Literature And History Of Turkish Or Turkic, 6(3), 797-810.

[7] Göver, İ. H. \& Yavuzer, H. (2015)., International periodical for the languages, literature and history of Turkish or Turkic, 10 (14), 345-362.

[8] Kıroğlu, K., Kesten, A. \& Elma, C. (2010). Socio-cultural and Economical problems of undergraduate international students in Turkey. Mersin University, Faculty of Education Journal, 6(2), 26-39.

[9] Lewis A, Ching G, Su Y 2013. A case study on the international students social adaptability in Taiwan a qualitative study. International Journal of Research Studiesin Psychology, 2(1): 18-22.

[10] Otrar, M., Ekşi, H., Dilmaç, B. \& Şirin, A. (2002). The Sources of Stress, Coping, and Psychological Well-Being among Turkish and Relative Societies' Students in Turkey. Theory and Application Faculty of Education, 2 (2), 473-506.

[11] Paksoy, H. M., Paksoy, S. \& Özçalıcı, M. (2012). Socio-Cultural Problems of Undergraduate International
Students in Turkey: The Sample of GAP Universities, Kahramanmaraş Sütçü İmam University The Journal of Faculty of Economic and Administrative Sciences, 2(2), 85-94.

[12] Pedersen, P. B. (1991). Counseling international students. Counseling Psychologist, 19, 10-58.

[13] SETA (2012). Küresel eğilimler 1şı̆̆ında Türkiye'de uluslararası ögrenciler, Ankara: SETA.

[14] Sodowsky, G. R., \& Plake, B. S. (1992). A study of acculturation differences among international people and suggestions for sensitivity to within-group differences. Journal of Counseling and Development, 71, 53-59.

[15] Talebloo B, Bin Baki R 2013. Challenges faced by international postgraduate students during their first year of study. International Journal of Humanity and Social Science 3(13): 3 .

[16] Titrek, O., Hashimi, S. H., Ali, A. S. \& Nguluma, H. F (2016). Challenges Faced by International Students in Turkey Anthropologist, 24(1): 148-156 (2016)

[17] Yıldırım, A .\& Şimşek, H. (2003). Sosyal bilimlerde nitel araştırma yöntemleri. Ankara: Seçkin Yayınları. 